\title{
Unidade de conservação, rodovia e território: uma análise da relação entre BR 319 e a Reserva de Desenvolvimento Sustentável Igapó Açú, Amazonas, Brasil
}

\author{
Conservation Unit, Road and Territory: an analysis of the relationship \\ between BR 319 and the Igapó-Açú Sustainable Development Reserve, \\ Amazonas, Brazil.
}

Davis Gruber Sansolo ${ }^{1}$

\begin{abstract}
Palavras-chave
Resumo

Áreas Protegidas

O presente trabalho trata das ameaças e potencialidades da relação

Amazônia

Planejamento. Turismo entre áreas protegidas, rodovias e o turismo na Amazônia. Refere-se a um estudo de caso, no interflúvio das bacias do Rio Purus e Madeira, no sul do estado do Amazonas, mais especificamente na Reserva de Desenvolvimento Sustentável Igapó Açu, atravessada pela rodovia BR 319. Por meio de revisão bibliográfica, documental e trabalhos de campo, elaborou-se uma análise sobre a potencialidade, fragilidades, ameaças e oportunidades do desenvolvimento territorial a partir do turismo na região. Conclui-se que a unidade de conservação pode ser um fator importante para o desenvolvimento territorial, pautado pela melhoria das condições sociais e resguardo da conservação da natureza, se a lógica do desenvolvimento turístico for subordinada a comunidade local.
\end{abstract}

$\begin{array}{ll}\text { Keywords } & \text { Abstract } \\ & \text { This paper is about the relationship between protected areas in the } \\ \text { Amazon, highways and tourism. This is a case study, in the } \\ \text { Protected Areas } & \text { interfluve of the Purus and Madeira River basins, in the south of the } \\ \text { Amazonia } & \text { state of Amazonas, specifically in the Igapó Açu Sustainable } \\ \text { Planning. Tourism } & \text { Development Reserve. This Reserve is crossed by the BR } 319 \text { road. } \\ & \text { Through bibliographical and documental review, and field work, it } \\ & \text { was made an analysis of the potential, fragilities, threats and } \\ & \text { opportunities of territorial development based on tourism. It is } \\ & \text { concluded that the protected area can be an important factor for } \\ \text { territorial development, based on the improvement of social } \\ \text { conditions and protection of nature, if the logic of tourism } \\ \text { development is subordinated to the local community. }\end{array}$

\footnotetext{
1 Programa de Pós-Graduação em Desenvolvimento Territorial na América Latina e Caribe da Universidade
} Estadual Paulista - UNESP. davis.sansolo@unesp.br 


\section{INTRODUÇÃO}

$\mathrm{Na}$ Amazônia as políticas de mobilidade humana, mercadorias e capital têm privilegiado a construção de rodovias que atravessam a floresta, causando impactos ambientais (FEARNSIDE; LAURANCE, 2002). O presente artigo resulta das atividades desenvolvidas em trabalhos de campo realizadas em 2010 no âmbito da Iniciativa Purus Madeira - IPUMA, para elaboração do Plano de Gestão de sete unidades de Conservação Estaduais na região de influência da Rodovia BR 319. As informações foram atualizadas até o ano de 2019.

Levantamos informações secundárias e primárias que ampararam a elaboração de uma proposta de uso público para o plano de gestão da Reserva de Desenvolvimento Sustentável (RDS) Igapó-Açu, uma das unidades de conservação envolvidas na IPUMA, promovendo uma análise estratégica como subsídio para elaboração de um plano de gestão para esta RDS.

Para Matus (apud HUERTAS, 1995), o Planejamento Estratégico Situacional considera a complexidade e as incertezas dos processos sociais, envolvendo o reconhecimento de problemas na realidade, com pontos de vista de diversos sujeitos sociais.

Para a identificação de problemas, como sugere Matus (apud HUERTAS, 1995), fez-se uma revisão bibliográfica e documental a respeito da situação da localidade estudada e de possíveis conexões inter-escalares, definindo-se uma estratégia de reconhecimento dos principais sujeitos relacionados ao uso público na unidade de conservação e estruturou-se um roteiro de entrevistas relacionado a visitação pública no território. Como instrumento de análise produziu-se uma matriz SWOT (Strengths, Weaknesses, Opportunities and Threats) já usada como método analítico em diversas pesquisas sobre unidades de conservação (BANZATO et al., 2012; REIHANIANA et al., 2012; SCOLOZZIA et al., 2014).

\section{A NOÇÃO DE ORDENAMENTO TERRITORIAL}

Sobre ordenamento territorial, Saquet (2013, p. 8) afirma que "o território resulta como conteúdo, meio e processo de relações sociais". $\mathrm{Ou}$ seja, ele produz e é produzido pelas relações sociais e de poder, sendo o território entendido como conflito social e mediador das relações de produção. De forma complementar Raffestin (1993) indica que natureza e cultura são elementos constitutivos do território, devendo este ser entendido como multidimensional, multiescalar e relacional, como um espaço de interação social, troca, cooperação, competição, mas, também de dominação, controle e poder. Os agentes que dominam se articulam para manter esse domínio, enquanto os que são dominados buscam resistir e inverter essa lógica. Assim, território é entendido como espaço ocupado, apropriado, controlado e contestado (RAFFESTIN, 1993; SANTOS, 1996; HAESBAERT, 2004; SAQUET, 2009).

Santos (1986), ao caracterizar as feições espaciais resultantes do processo histórico de produção do território, indica que há "espaços 
fluidos", onde existe uma concentração tecnoinformacional que possibilita a fluidez do capital e há "espaços rugosos", nos quais as estruturas tecno-informacionais são rarefeitas, exercendo-se uma resistência ao fluxo de informações, capital e população, dificultando a expansão capitalista sobre o território. De forma análoga, Moura e Magalhães (2011) denominam como impedância territorial, uma resistência que as dificuldades representadas pelas normas ambientais, a exemplo das unidades de conservação, exercem um papel de contenção sobre o processo de urbanização dos territórios.

Portanto, as áreas protegidas podem exercer uma função de resistência ou de impedância, em relação a vetores de pressão induzidos pelas rodovias sobre a floresta, que "abrem a floresta permitindo o avanço das madeireiras, pequenos e grandes produtores, causando um desmatamento de até $50 \mathrm{~km}$ a cada lado da rodovia" (BECKER, 2001, p. 152153).

O Sistema Nacional de Unidades de Conservação - SNUC (BRASIL, 2000) é composto por unidades de conservação de proteção integral e as unidades de conservação de uso sustentável. Nas reservas de desenvolvimento sustentável (RDS), só é permitida a habitação por comunidades tradicionais, sendo possível a realização de atividades além do extrativismo como a agricultura, pecuária e pesca, dentre outras, inclusive o turismo.

O chamado efeito "espinha de peixe", causado por modelos de ocupação da fronteira agrícola na Amazônia, tem as rodovias como vetores do processo de desmatamento (ESCADA; ALVES, 2001; SAITO et al., 2011). Como meio de contenção dessa dinâmica, a Política Nacional do Meio Ambiente (BRASIL, 1981), tem como instrumento os processos de licenciamento ambiental.

A existência de unidades de conservação nas áreas de influência das rodovias determina uma série de procedimentos para o licenciamento ambiental. A título de compensação, os recursos financeiros podem ser destinados para unidades de conservação existentes, podem ser criadas unidades de conservação e outras áreas protegidas, como terras indígenas, próximas a rodovias. Um dos casos relevantes deste processo foi o da rodovia BR 163, que liga Cuiabá a Santarém. Furtado e Monteiro (2006) apontam resultados positivos na criação de unidades de conservação ao longo da rodovia, demonstrando que o desmatamento tem sido menor onde há áreas protegidas.

\section{O caso da Rodovia BR 319: para ampliar o debate}

A Rodovia BR 319 foi projetada para ligar Porto Velho a Manaus (Mapa 1), durante a ditadura militar (entre 1964 e 1985) baseada no ideário de integrar e ocupar a região Amazônica, como estratégia geopolítica. (FEARNSIDE; GRAÇA, 2009a). Entre 1968 e 1973, sob o interflúvio dos Rios Madeira e Purus, foi aberta a BR 319, inaugurada em 1976 (FEARNSIDE; GRAÇA, 2009b), com a falta de manutenção, em 1988, a estrada ficou intransitável, sendo desativada. 
Mapa1 - Localização da BR 319.

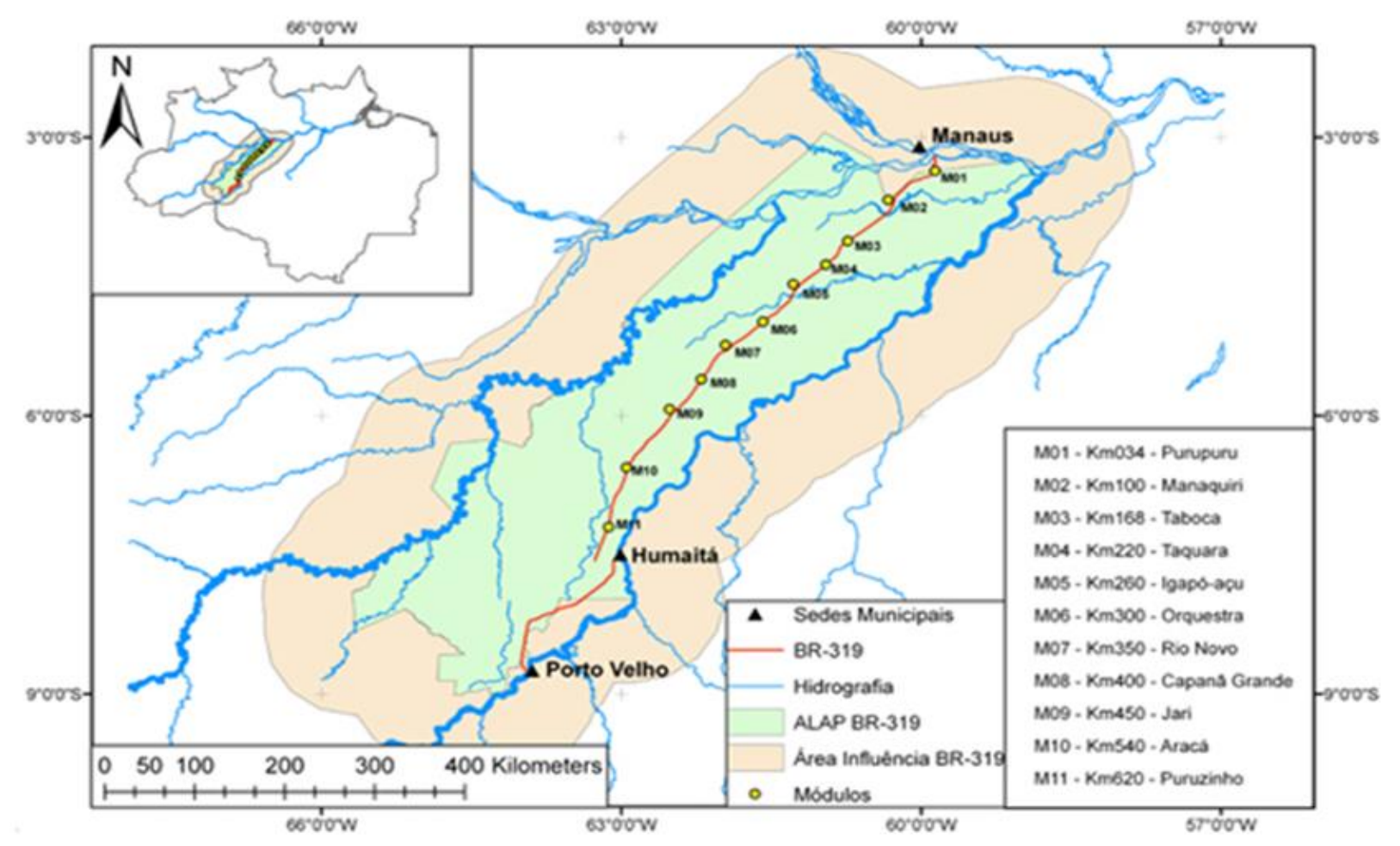

Fonte: INPA, 2014

Desde então, a recuperação da rodovia tem sido alvo de especulações em vários momentos e governos. Esteve incluída no Plano Brasil em Ação, do Presidente Fernando Henrique Cardoso, no Plano Avança Brasil e prevista no Plano Plurianual, entre 2004 e 2007. Segundo Lima (2007), em 2005, o Ministério do Transporte deu início às obras de recuperação da estrada. Entretanto, o Ministério do Meio Ambiente exigiu o licenciamento ambiental, embargando a continuidade das obras.

Com respeito à proposta do desenvolvimento econômico na região ao longo da BR 319, Lima (2007) apontou a agropecuária, piscicultura, transporte e turismo como setores promissores. A autora aponta o potencial aumento anual do turismo e o desenvolvimento de empreendimentos hoteleiros na região, em especial para o desenvolvimento da hotelaria de floresta, indicando que se hospedaram no Amazonas em hotéis urbanos 470.992 hóspedes e em hotéis na floresta, 227.554.

As unidades de conservação podem ser consideradas uma rugosidade, formas geográficas naturais herdadas, no contexto da paisagem (SANTOS, 1996), pois são objetos de conteúdo de valor (dados pela sociedade à floresta e seus atributos ambientais), pois são objetos-conteúdo, cujo valor dado pela sociedade à floresta e seus atributos ambientais, se expressam pela institucionalidade excepcional (BRASIL, 2000) que retira os territórios protegidos, do mercado legal de terras. Potencialmente, tornam-se 
territórios de resistência ao desmatamento, diante dos cenários pessimistas de desmatamento estudados por Fearnside e Graça (2009a). Nas áreas de influência da
BR319 foram instituídas 21 unidades de conservação, sendo 10 federais e 11 estaduais (Mapa 2).

Mapa 2. Unidades de Conservação no Entorno da BR 319.

1. FLONA do Iquiri

2. RESEX Ituxi

3. PARNA do Mapinguari

4. ESEC Serra dos Três Irmãos

5. RESEX Médio Purus

6. RESEX Canutama

8. FLONA de Balata-Tufari

9. FES Tapauá

10. PARNA Nascentes do Lago Jari

12. RDS Piagaçu-Purus

13. RDS Igapó-Açu
7. FES Canutama

11. REBIO do Abufari
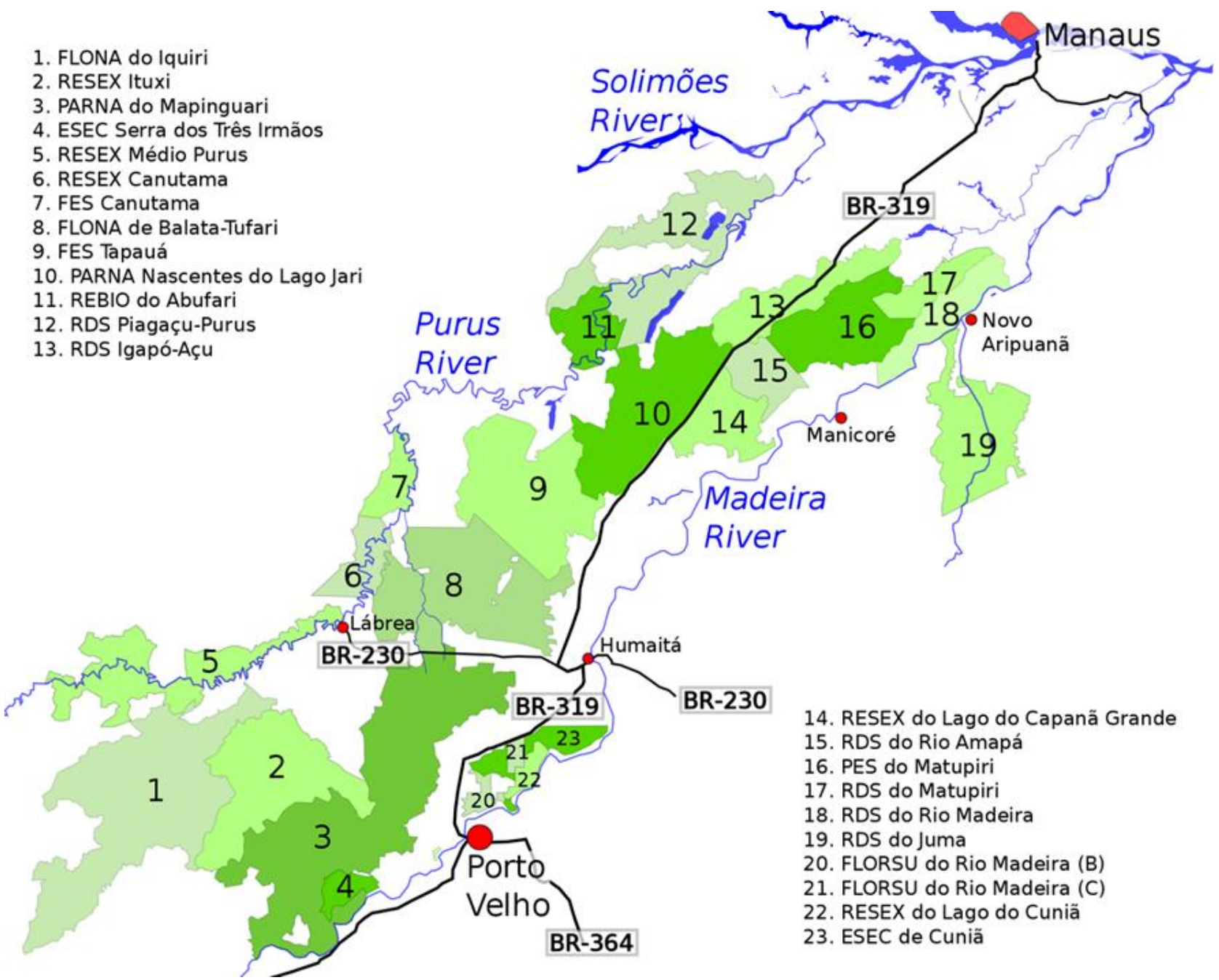

Fonte: https://pt.wikipedia.org/wiki/BR-319. Acessado em agosto de 2019.

O município de Careiro Castanho, turismo

atualmente pode ser considerado estratégico para a região. É nele onde se apoiamos que cruzam essa rodovia, pois as condições de tráfego ainda são precárias, sem qualquer infraestrutura e pavimentação.

BR 319: unidades de conservação e

O turismo no Amazonas entre 2003 e 2008 cresceu 14,7\%. Entre 2010 e 2014 esse número foi de 675.713 para 1.168 .612 turistas (AMAZONAS, 2015). Os indicadores utilizados para o turismo se basearam na ocupação de meios de hospedagem urbana, hotéis de selva, 
segmento da pesca esportiva e cruzeiros marítimos.

Entre 1992 e 2000 houve um incremento de aproximadamente $2790 \%$ nas atividades de pesca esportiva no Amazonas (BEGROW, 2002). Em 2010, foram registrados 6.630 e em 2014, 9.875 turistas (AMAZONAS, 2015) nesta atividade, que conforme Souza (2014), gerou a expectativa de movimentação de 4 milhões de dólares, com $95 \%$ dos turistas de origem norte americana interessados em pesca esportiva. Em notícia recente (G1, 2018), representantes do Ministério do Turismo afirmaram que a pesca esportiva movimenta $\mathrm{R} \$ 50$ milhões ao ano, trazendo 10 mil turistas ao ano ao estado.

Esses dados são significativos, pois a região do interflúvio Madeira-Purus ainda é pouco conhecida pelo mercado do turismo de pesca esportiva, não obstante já se constata a existência dessa prática em algumas localidades.

A RDS do Igapó Açu encontra-se no entroncamento entre a BR 319 e o Rio IgapóAçu, sendo a principal característica da região a presença de vegetação de igapó com predominância da macacarecuia (Couroupita guianensis). O rio possui diversas espécies de peixe, destacando-se o tucunaré-açu (Cichla temensis), atrativo para os pescadores amadores.

A IPUMA foi criada a partir da necessidade do estado do Amazonas de implementar sete novas unidades de conservação, além das que já existiam na região do entorno da BR 319, no interflúvio dos rios Purus e Madeira. Em 2010, a Secretaria de Estado do Meio Ambiente e Desenvolvimento Sustentável do Amazonas (SDS/AM) contratou a Fundação Amazônica de Defesa da Biosfera para dar início ao processo assumindo a execução orçamentária e montando a equipe da IPUMA.

O mosaico Igapó-Açu Matupiri (Mapa 3) destaca-se por ser, entre as unidades de conservação ao longo da BR 319, a mais acessível partindo de Manaus, sendo este mosaico proposto em 2006 depois de decretada Área de Limitação Administrativa Provisória (ALAP) no entorno da BR-319. Em 2009, por meio do Decreto (AMAZONAS, 2009), criou-se a Reserva de Desenvolvimento Sustentável Igapó-Açu.

A localização da comunidade do IgapóAçu é estratégica: a rodovia favorece o acesso a três Unidades de Conservação e a uma área indígena. No entroncamento da estrada com o Rio Igapó Açu localiza-se um povoado, formado durante a década de 1970, quando a localidade era movimentada pelo fluxo e parada de caminhões, ônibus de passageiros e automóveis. Habitações, bares e uma pousada foram erguidos, servindo como ponto de apoio aos viajantes pelos próximos vinte anos. 
Mapa 3: Localização do Mosaico Matupiri Igapó-Açu
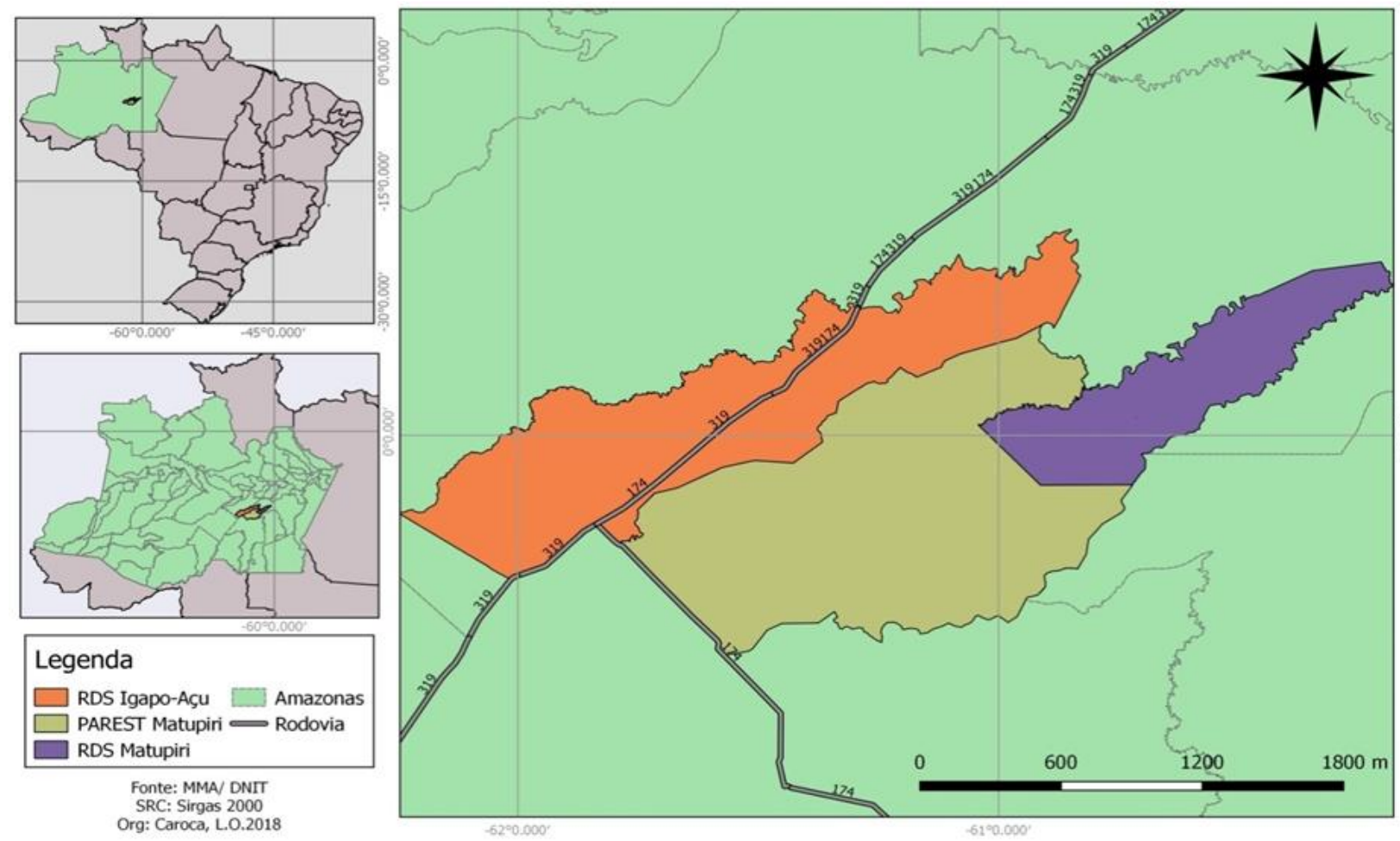

Fontes: BRASIL, 2018; DNIT, 2018.

A partir da década de 1980, com a deterioração do pavimento da estrada, o fluxo de veículos diminuiu, forçando um processo de emigração da população. Em 2018, o povoado de 200 famílias (ISA, 2018) é dividido pelo rio, possui algumas habitações, cinco bares e uma pousada. Embora o fluxo de veículos seja pequeno, recebem viajantes que buscam os rios da região como local para pesca e caça. Durante o período de quatro dias, observaramse em frente à pousada caminhões preparados para acampamento com famílias, grupos de motoqueiros em viagem de lazer e caminhonetes de pescadores amadores.

A RDS do Igapó Açu é habitada por agricultores, pescadores e extrativistas que vivem de subsistência. Ainda que em estado precário, é possível chegar ao Rio Igapó Açu pela rodovia e de lá se acessar, pelo rio IgapóAçu, a RDS do Matupiri. Vindo de Porto Velho só é possível trafegar pela rodovia nos meses mais secos ao longo do ano.

Não há policiamento rodoviário, fiscalização ambiental, estrutura de socorro mecânico, nem de apoio à saúde ou acidentes. Os riscos de visitação à RDS do Igapó Açu são muitos, desde exposição a acidentes com animais peçonhentos, como as serpentes dormideiras (Sibynomorphus mikania), a jararaca (Bothrops jararaca) e a cobra cipó (Chironius sp.), mamíferos predadores, bem como exposição a endemias como malária, dengue e leishmaniose.

Durante entrevista realizada com a gestora da RDS, em 2010, foi informado que já ocorria visitação na região, embora não 
existam registros oficiais do número de turistas. A atividade gerava renda para cozinheiras, mateiros e piloteiros, todos residentes na unidade de conservação. As principais atividades relatadas foram a pesca esportiva e safaris ilegais de caça, praticados por turistas de alto poder aquisitivo. A expectativa da gestora em relação à pavimentação da estrada era de aumento do volume de visitantes, o que poderia trazer melhorias para as comunidades residentes.

A atividade de pesca esportiva é motivo de desavença entre alguns pescadores pois é uma disputa pelo recurso pesqueiro. Embora não se possa afirmar que a atividade ofereça pressão sobre o estoque pesqueiro pela falta de registros sobre o número de visitantes para a área, pode-se afirmar que, do ponto de vista social, há um ponto de conflito.

Uma das principais lideranças locais, a proprietária do único meio de hospedagem existente, informou que vivia e trabalhava na região há 32 anos. A pousada localiza-se na beira da rodovia e próxima ao Rio Igapó-Açu onde há uma balsa para travessia de veículos. Ela era empregada da pousada e em 1993 tornou-se proprietária, foi também presidente da Associação de Moradores. Segundo ela, confirmando as informações da gestora da RDS, a visitação era feita por pesquisadores, pescadores provenientes de Manaus, pescadores trazidos por operadoras de pesca esportiva e por grupos de caçadores.

Entre julho e agosto há um movimento importante e ocupação frequente da pousada. No período de janeiro, durante as chuvas, não aparecem visitantes devido à total impossibilidade de trânsito. Os viajantes, cujo principal interesse é a pesca esportiva vêm de São Paulo, Brasília, Pará e outras localidades. A maioria são homens, vem de carro de Manaus, alugam barcos e se alimentam na pousada. Ela confirmou que existiam grupos que chegavam para caçar e não gostava quando os pescadores levavam o peixe para fora da região, pois não deixam nenhum benefício, sugerindo que haja algum tipo de cobrança ou ajuda financeira à comunidade que poderia ser cobrado dos pescadores amadores, bem como algum tipo de acordo de pesca estabelecendo normas e limites aos pescadores esportivos ou amadores.

Em seu depoimento indicou o desejo do aumento de visitantes. Ela entendia que deveria ter outros empreendimentos além do dela, mas deveria haver organização da comunidade em relação ao turismo, o que veio ocorrer em 2014.

Em 2013 foi fundada na RDS, a Associação Mil Maravilhas de Ecoturismo, com vistas de promover o protagonismo da população local na organização da atividade turística. Conforme Rezende (2016), em 2014 foram realizadas reuniões para elaboração do plano de gestão participativo e constituído o Conselho Gestor Deliberativo.

Um problema importante é a dificuldade de comunicação, pois só existe um telefone público ligado à energia solar. Com muita frequência ele apresenta defeito deixando a localidade sem comunicação com o exterior.

A atividade de pesca esportiva é praticada dentro da RDS do Igapó Açu, mas também avança na RDS do Matupiri e no 
Parque Estadual do Matupiri. Conforme relato de pescadores locais, alguns visitantes chegam de hidroavião e alugam embarcações locais. Até 2010 e ainda hoje, o que se percebe é que a visitação em pequeno volume é uma atividade que ocorre sob o comando externo e, portanto, os locais ficam subjugados a uma lógica econômica externa, que se impõe sobre o lugar.

\section{Análises de informações sobre a gestão da RDS}

Após a revisão bibliográfica e a realização da pesquisa de campo elaboramos a análise de conteúdo (BARDIN, 2010), extraídos a posteriori, de entrevistas com sujeitos locais. A síntese dos conteúdos foi organizada em uma matriz SWOT - Fortalezas, Fragilidades, Oportunidades e Ameaças, (Quadro 1) expondo as potencialidades, limitações e desafios para o desenvolvimento do programa de uso público para a RDS.

A matriz permitiu interpretar que a situação geográfica da RDS Igapó Açu é estratégica para o apoio das políticas de conservação como o Programa de Áreas Protegidas da Amazônia (ARPA), no qual a RDS está englobada dentre as 105 áreas protegidas.

Trata-se de uma importante porção da Amazônia, que pode ser considerada como espaço de impedância, ou uma rugosidade espacial (SANTOS, 1996), que poderá influenciar na contenção do desmatamento na região. O sul do Estado do Amazonas e a RDS do Igapó-Açu estão contidos no chamado arco de desflorestamento da Amazônia (BARNI et al., 2015). A restauração da rodovia BR 319, poderá desencadear, caso não sejam tomadas as devidas medidas de contenção, a expansão do desflorestamento.

Quadro 1 - Matriz SWOT para o Programa de Uso Público.

\begin{tabular}{|c|c|c|c|}
\hline FORTALEZAS & FRAGILIDADES & OPORTUNIDADES & AMEAÇAS \\
\hline $\begin{array}{c}\text { Ictiofauna para pesca amadora } \\
\text { nos lagos e rios das RDS do } \\
\text { Igapó Açu e Matupiri }\end{array}$ & $\begin{array}{l}\text { Inexistência de pesquisas e } \\
\text { monitoramento da ictiofauna; }\end{array}$ & $\begin{array}{c}\text { Elaboração do Plano de Manejo } \\
\text { com a participação das } \\
\text { comunidades, favorecendo a } \\
\text { organização comunitária com } \\
\text { vistas ao apoio e organização } \\
\text { das atividades de Uso Público. }\end{array}$ & $\begin{array}{c}\text { Fragilidade institucional } \\
\text { do governo do Estado para } \\
\text { mediação de conflitos, e } \\
\text { manutenção de simetria de } \\
\text { poder entre agentes } \\
\text { externos e a comunidade } \\
\text { no que se refere a pesca } \\
\text { esportiva }\end{array}$ \\
\hline $\begin{array}{c}\text { Reação da comunidade geradas } \\
\text { pela pesca esportiva } \\
\text { desordenadas já existentes. }\end{array}$ & $\begin{array}{c}\text { Estado incipiente da } \\
\text { organização comunitária diante } \\
\text { das pressões atuais e futuras do } \\
\text { crescimento do turismo de pesca } \\
\text { esportiva }\end{array}$ & $\begin{array}{l}\text { Recursos do ARPA e do DENIT } \\
\text { para implementação de plano } \\
\text { de manejo participativo }\end{array}$ & $\begin{array}{l}\text { Geração de expectativas } \\
\text { relativas a atratividade da } \\
\text { região que não venham a } \\
\text { ser atendidas }\end{array}$ \\
\hline $\begin{array}{l}\text { Mata de igapó no período de } \\
\text { cheia para canoagem, } \\
\text { preferencialmente com canoas } \\
\text { tradicionais. }\end{array}$ & $\begin{array}{l}\text { Ausência de protocolos de } \\
\text { segurança para o } \\
\text { desenvolvimento do turismo na } \\
\text { RDS Igapó Açu; }\end{array}$ & $\begin{array}{l}\text { Interesse internacional para se } \\
\text { conhecer a Amazônia }\end{array}$ & $\begin{array}{c}\text { Ausência de política perene } \\
\text { e clara que articule } \\
\text { turismo, conservação da } \\
\text { natureza e } \\
\text { desenvolvimento social }\end{array}$ \\
\hline $\begin{array}{l}\text { Conhecimento da população } \\
\text { sobre os elementos e dinâmica } \\
\text { da natureza local que possa ser } \\
\text { apresentada aos visitantes }\end{array}$ & $\begin{array}{l}\text { Ausência de treinamento da } \\
\text { mão de obra local para o } \\
\text { desenvolvimento de atividades } \\
\text { recreacionais com algum grau } \\
\text { de risco. }\end{array}$ & $\begin{array}{c}\text { Existência de organizações } \\
\text { internacionais interessadas em } \\
\text { apoiar projetos de } \\
\text { desenvolvimento sustentável na } \\
\text { Amazônia para manutenção da } \\
\text { biodiversidade; }\end{array}$ & $\begin{array}{l}\text { Predominância do } \\
\text { conhecimento externo em } \\
\text { relação ao conhecimento da } \\
\text { comunidade }\end{array}$ \\
\hline
\end{tabular}




\begin{tabular}{|c|c|c|c|}
\hline $\begin{array}{l}\text { Inventário participativo, } \\
\text { detalhado dos recursos para o } \\
\text { desenvolvimento do Uso } \\
\text { Público }\end{array}$ & $\begin{array}{c}\text { Descontinuidade na } \\
\text { implementação do plano de } \\
\text { manejo }\end{array}$ & $\begin{array}{c}\text { Conhecimento prévio de } \\
\text { visitantes, sobre a região, tendo } \\
\text { em vista atividades de lazer e } \\
\text { turismo }\end{array}$ & $\begin{array}{l}\text { Potencial aumento da } \\
\text { visitação desordenada, } \\
\text { devido à proximidade de } \\
\text { Manaus, considerando a } \\
\text { eminente pavimentação da } \\
\text { BR 319, política de } \\
\text { desenvolvimento do } \\
\text { turismo na Amazônia. }\end{array}$ \\
\hline $\begin{array}{c}\text { Presença de operadoras de } \\
\text { pesca }\end{array}$ & $\begin{array}{l}\text { Relações econômicas } \\
\text { assimétricas entre operadoras } \\
\text { de pesca e comunidade }\end{array}$ & $\begin{array}{c}\text { Domínio das atividades de uso } \\
\text { público por parte de } \\
\text { intermediários vinculados ao } \\
\text { negócio turístico }\end{array}$ & $\begin{array}{c}\text { Hegemonia das atividades } \\
\text { turísticas por parte de } \\
\text { sujeitos externos a } \\
\text { comunidade }\end{array}$ \\
\hline $\begin{array}{l}\text { Diversidade de unidades de } \\
\text { paisagem }\end{array}$ & $\begin{array}{c}\text { Extensão territorial da UCs com } \\
\text { baixíssima densidade } \\
\text { demográfica e ausência de } \\
\text { estrutura de fiscalização; }\end{array}$ & $\begin{array}{c}\text { Desenvolvimento do sentido de } \\
\text { pertencimento (educação } \\
\text { ambiental) das comunidades da } \\
\text { RDS do Igapó Açu, tendo a } \\
\text { paisagem como fonte e } \\
\text { desenvolvimento de estratégia } \\
\text { de proteção e uso das UCs de } \\
\text { forma integrada; } \\
\end{array}$ & $\begin{array}{c}\text { Desconsideração da } \\
\text { dinâmica da natureza da } \\
\text { região na implantação da } \\
\text { rodovia e das estruturas de } \\
\text { apoio ao turismo; }\end{array}$ \\
\hline Igarapés para banho; & $\begin{array}{l}\text { Longa distância do núcleo } \\
\text { urbano (Careiro Castanho) de } \\
\text { apoio às atividades turísticas } \\
\text { dificultando fiscalização e } \\
\text { prevenção de impactos } \\
\text { ambientais. }\end{array}$ & $\begin{array}{l}\text { Implementação de um sistema } \\
\text { de controle e fiscalização e } \\
\text { segurança na RDS; }\end{array}$ & $\begin{array}{l}\text { Falta de recursos para } \\
\text { implementação do plano de } \\
\text { manejo e o decorrente } \\
\text { programa de uso público }\end{array}$ \\
\hline $\begin{array}{c}\text { Pequenas praias (no período } \\
\text { vazante) para acampamentos, } \\
\text { piqueniques e pesca } \\
\text { desembarcada; }\end{array}$ & $\begin{array}{c}\text { Processo de emigração da } \\
\text { população pela carência de } \\
\text { estruturas sociais como } \\
\text { equipamentos de saúde pública, } \\
\text { educação e meios de } \\
\text { comunicação; }\end{array}$ & $\begin{array}{l}\text { Elaboração de projetos de } \\
\text { qualificação dos recursos } \\
\text { voltados ao Uso Público; }\end{array}$ & $\begin{array}{l}\text { Abandono da região por } \\
\text { parte do poder público }\end{array}$ \\
\hline $\begin{array}{c}\text { Agroextrativismo comunitário } \\
\text { nas RDS; }\end{array}$ & $\begin{array}{c}\text { Estrutura de recepção } \\
\text { deficiente na RDS do Igapó Açu } \\
\text { e ausente na RDS do Matupiri } \\
\text { (hospedagem, alimentação); }\end{array}$ & $\begin{array}{c}\text { Valorização da produção de } \\
\text { agricultura ecológica para o } \\
\text { mercado nacional e } \\
\text { internacional, tornando a } \\
\text { visitação aos produtores um } \\
\text { atrativo; }\end{array}$ & $\begin{array}{l}\text { Supervalorização da } \\
\text { mercadoria agroecológica } \\
\text { pelo mercado externo, } \\
\text { deixando o mercado } \\
\text { interno desabastecido. }\end{array}$ \\
\hline $\begin{array}{l}\text { Aproveitamento da produção } \\
\text { local para alimentação dos } \\
\text { visitantes; }\end{array}$ & $\begin{array}{c}\text { Ausência de ações voltadas para } \\
\text { segurança alimentar }\end{array}$ & $\begin{array}{c}\text { A pavimentação oportunizará a } \\
\text { comercialização dos produtos } \\
\text { locais e a importação de } \\
\text { produtos complementares de } \\
\text { outras regiões }\end{array}$ & $\begin{array}{l}\text { Substituição de alimentos } \\
\text { locais por alimentos de fora }\end{array}$ \\
\hline $\begin{array}{c}\text { Estrutura institucional única } \\
\text { para as três UCs voltada à } \\
\text { coordenação do Uso Público } \\
\text { como programa estratégico } \\
\text { para gestão. }\end{array}$ & $\begin{array}{l}\text { Restauro da estrada sem o } \\
\text { plano de manejo implementado; }\end{array}$ & $\begin{array}{c}\text { Otimização de recursos para } \\
\text { conservação de uma área ampla }\end{array}$ & $\begin{array}{l}\text { Insuficiência de recursos } \\
\text { que atenda as três } \\
\text { unidades de conservação } \\
\text { que compõe o mosaico de } \\
\text { UCs locais }\end{array}$ \\
\hline $\begin{array}{c}\text { Existência de espaços } \\
\text { convivência como campo de } \\
\text { futebol e bares na RDS do } \\
\text { Igapó Açu, igarapés e o próprio } \\
\text { Rio Igapó Açu. }\end{array}$ & $\begin{array}{l}\text { Corpos d'água ao longo da } \\
\text { rodovia com fácil acessibilidade } \\
\text { sem proteção alguma; }\end{array}$ & $\begin{array}{l}\text { Implementação do plano de } \\
\text { manejo como oportunidade para } \\
\text { atração de recursos para } \\
\text { infraestrutura básica }\end{array}$ & $\begin{array}{c}\text { Ausência previsão de } \\
\text { recursos para implantação } \\
\text { de infraestrutura básica na } \\
\text { comunidade }\end{array}$ \\
\hline $\begin{array}{l}\text { Navegação para observação da } \\
\text { natureza no Rio Igapó Açu; }\end{array}$ & $\begin{array}{l}\text { Ausência de tecnologia } \\
\text { ambientalmente compatível na } \\
\text { RDS do Igapó Açu; }\end{array}$ & $\begin{array}{l}\text { Tecnologias tradicionais como } \\
\text { canoas; Presença de } \\
\text { pesquisadores do INPA pode } \\
\text { trazer respostas as } \\
\text { necessidades locais }\end{array}$ & $\begin{array}{c}\text { Insuficiência de pesquisas } \\
\text { socioambientais em apoio a } \\
\text { gestão do território }\end{array}$ \\
\hline
\end{tabular}




\begin{tabular}{|c|c|c|c|}
\hline $\begin{array}{c}\text { Aproveitamento do } \\
\text { conhecimento tradicional sobre } \\
\text { a natureza local; }\end{array}$ & $\begin{array}{c}\text { Ausência de inventário de fauna } \\
\text { e flora que para orientação da } \\
\text { visitação }\end{array}$ & $\begin{array}{c}\text { Valorização internacional pela } \\
\text { pesca esportiva }\end{array}$ & $\begin{array}{c}\text { Interesse e promoção de } \\
\text { Caça esportiva } \\
\text { clandestina; Pesca } \\
\text { esportiva irregular e sem } \\
\text { fiscalização; }\end{array}$ \\
\hline $\begin{array}{c}\text { Presença avifauna endêmica; } \\
\text { Ausência de inventário de } \\
\text { avifauna }\end{array}$ & $\begin{array}{c}\text { Interesse internacional pela } \\
\text { observação de aves }\end{array}$ & $\begin{array}{c}\text { Ausência de Infraestrutura } \\
\text { para observadores de aves }\end{array}$ \\
\hline $\begin{array}{c}\text { Mastofauna importante e } \\
\text { possível de ser avistada. } \\
\text { Conhecimento tradicional } \\
\text { sobre a fauna local, hábitos e } \\
\text { locais de avistamento; }\end{array}$ & $\begin{array}{c}\text { Ausência infraestrutura de } \\
\text { apoio à visitação (transporte, } \\
\text { sinalização, alojamentos, } \\
\text { abrigos, comunicação). }\end{array}$ & $\begin{array}{c}\text { Eventos internacionais no } \\
\text { Brasil que divulgam a } \\
\text { Amazônia }\end{array}$ & $\begin{array}{c}\text { Atração de turistas sem a } \\
\text { infraestrutura adequada }\end{array}$ \\
\hline
\end{tabular}

Fonte: o autor.

As ameaças externas são evidentes nas falas dos entrevistados. O crescimento do turismo no Amazonas pode ser interpretado como oportunidade para mobilização e fortalecimento das comunidades locais (PROENÇA et al., 2016), favorecendo uma resistência ao desflorestamento, desenhado na forma de espinha de peixe, tão comum na região Amazônica (BARNI et al. 2015). Os parcos investimentos governamentais efetuados na região dificultam permanência da comunidade e facilitam os exploradores externos a praticarem todo tipo de irregularidades ambientais, como a pesca e a caça predatórias, proibidas pela lei brasileira.

A natureza tem sido fator de atração de visitantes. A hidrografia e a biota, sobretudo a ictiofauna, oferecem as condições para o turismo de pesca. A mata de igapó, permanentemente inundada, favorece passeios de canoa e a proximidade da floresta dentro do meio aquático, o que é inusitado. Os igarapés, em algumas áreas mais abrigadas da exposição ao sol, são opção para banhos devido à temperatura mais amena das águas. Além da diversidade da avifauna há outras potencialidades para o incremento da visitação. Entretanto, a precariedade da estrutura para receber visitantes, sem que haja segurança para realização de atividades junto à natureza, se torna uma ameaça aos atuais e futuros turistas. A única opção de hospedagem e alimentação torna a permanência no local um desafio.

A presença de uma comunidade que habita a região há muitos anos, pode ser um fator favorável, diante da possibilidade do desenvolvimento do turismo de base comunitária (BARTHOLO et al. 2009), que poderia dar a substância necessária a um programa de uso público da unidade de conservação, em especial com as características territoriais e ambientais da RDS do Igapó-Açú. Tal programa demandaria organização da hospedagem, que poderia ser pelo compartilhamento das residências (se adaptadas para receberem visitantes), alimentação e atividades de entretenimento, 
tendo como foco os espaços comunitários: rios, roças, floresta.

\section{CONSIDERAÇÕES FINAIS}

Ainda que o volume de turistas na Amazônia não seja expressivo como em outras regiões no Brasil e no caso das unidades de conservação, esse número, em termos absolutos, seja inferior aos visitantes em unidades de conservação próximas ao litoral, o turismo é uma realidade na região Amazônica. Nota-se também que as políticas públicas de turismo e de conservação da natureza indicam que há interesse que o turismo seja uma opção que compatibilize o desenvolvimento econômico, social e a conservação da natureza.

A implementação de unidades de conservação, diante de outras ações como a abertura de estradas para a viabilização da fluidez de mercadorias e pessoas, nos parece uma ação paliativa, que possui uma função de resistência ao modelo de ocupação que provoca o efeito de espinha de peixe ou a ampliação do desmatamento da floresta Amazônica. Tratase de modelo de ocupação a ser repensado, tendo a floresta, os rios e as populações locais como valores basais para um modelo de desenvolvimento que promova bem-estar social e conservação da natureza.

Não parece evidente imaginar que uma rodovia de aproximadamente $1000 \mathrm{~km} \mathrm{em}$ meio à floresta amazônica, possa ser viável economicamente, tendo em vista a necessidade de manutenção constante, em função do regime climático e hidrológico. O calor, as chuvas e a tendência de resiliência da floresta, associados ao uso, mesmo que de baixa intensidade, irá causar, como já ocorreu, a degradação do pavimento e demandará uma infraestrutura de apoio e de manutenção que hoje não se justificam economicamente, considerando os polos que serão unidos. Embora as cargas possam vir a ganhar em velocidade de transporte, os custos são mais altos do que a via fluvial. A influência das hidroelétricas de Jirau e Santo Antônio em Rondônia podem trazer uma instabilidade para a operação e navegação no Rio Madeira o que poderá despertar o interesse pelo transporte de cargas pela Rodovia BR 319.

As unidades de conservação assumem um papel no território além do objetivo de proteger a biodiversidade. Exercem um papel de contenção de um modelo de desenvolvimento perverso e excludente e assumem papel de mobilizadoras da participação política das comunidades para que estas se organizem e se tornem soberanas sobre seus territórios, diante dos novos desafios que chegam com as estradas e a expansão do desenvolvimento capitalista sobre a região.

As RDS do Igapó-Açu e RDS do Matupiri já são utilizadas para o turismo, com algum controle e participação das comunidades locais no processo. A restauração da estrada pode vir a incrementar o uso de rios e da floresta, com a finalidade de lazer e recreação e, portanto, um potencial para o desenvolvimento econômico, tendo entre outras atividades o turismo como fator de dinamização.

Assim, as unidades de conservação ao longo da BR 319 assumem um importante 
papel para contenção da degradação das florestas e rios, servindo como territórios de resistência. Tanto pelo vértice de Rondônia, onde hoje as praias do rio Purus já são usadas em festas sazonais, quanto por Manaus, onde o turismo internacional já constitui um fator de pressão sore a ictiofauna, além da prática proibida da caça esportiva.

$\mathrm{Na}$ RDS Igapó-Açú, para o desenvolvimento de um programa de uso público são essenciais ações de educação ambiental como estratégia de envolvimento da comunidade, para que esta possa se fortalecer e se beneficiar da unidade de conservação, de forma que se incentive o sentido de pertencimento dessas comunidades às unidades de conservação onde vivem. Também um subprograma de visitação e turismo é estratégico, pois embora hoje o turismo já seja uma realidade na região do Igapó Açu, a tendência é que se desenvolva ainda mais no futuro. O risco, neste caso, é o seu desenvolvimento definido a partir do protagonismo externo, o que pode potencializar a exclusão social e a promoção e conflitos entre moradores e a gestão da área protegida.

O desenvolvimento da estratégia de conservação ambiental baseada nas áreas protegidas localizadas ao longo das rodovias deve vir acompanhado da melhoria de condições de vida da população local.

Para que programas de uso público possam ser desenvolvidos na RDS Igapó Açu se requer infraestrutura básica que é inexistente atualmente, como saneamento básico, tratamento e abastecimento d'água, bem como um sistema de comunicação eficiente. Além disso, é necessário que se incentive e se proporcione o desenvolvimento de estruturas de apoio ao turismo, e a educação ambiental, iniciativas escassas na região.

A implementação efetiva das unidades de conservação na região sul do Estado do Amazonas tem fundamental importância geopolítica, pois poderá exercer resistência ao modelo de desenvolvimento que desconsidera a biodiversidade da Amazônia e das populações que lá residem e vivem da terra e dependem da floresta e dos rios. Valorizar para o mundo o conhecimento tradicional e a biodiversidade constituem inspiração para o estabelecimento do diálogo com possíveis visitantes que desejem ampliar as suas experiências de vida e que trazem suas experiências e conhecimento para os habitantes da região. É com base na construção de relações dialógicas que o turismo pode gerar benefícios para a Amazônia e para o mundo.

\section{REFERÊNCIAS}

AMAZONAS. Decreto $\mathbf{n}^{\mathbf{0}} \mathbf{2 8 . 4 2 0}$, de 27.03.2009: cria a Reserva de Desenvolvimento Sustentável Igapó-Açu nos Municípios de Borba, Manicoré e Beruri, e dá outras providências, 2009. Disponível em : $<$ http://www.pge.am.gov.br/wpcontent/uploads/2017/12/Vade-Mecum-.pdf> Acessado: Dezembro de 2019.

AMAZONAS. Amazonastur. Síntese dos indicadores de turismo do Amazonas, 20032014. Manaus, Amazonastur, 2015. Disponível em: <https://docplayer.com.br/17419914-Sintesedos-indicadores-de-turismo-do-amazonas-20032014.html>. Acessado: Janeiro de 2020.

AMAZONAS. Secretaria de Estado da Região Metropolitana de Manaus. Plano de desenvolvimento sustentável e integrado. Manaus, Secretaria de Estado da Região 
Metropolitana de Manaus. Consórcio VetecValente, 2010.

BANZATO, B. M.; FAVERO, J. M.; AROUCA, J. A. C.; CARBONARI, J. H.B. Análise ambiental de unidades de conservação através dos métodos swot e gut: $O$ caso do parque estadual restinga de Bertioga. RBGA (Pombal - PB - Brasil) v.6, n.1, p. 38-49 Janeiro/dezembro de 2012. Disponível em: $<$ https://www.gvaa.com.br/revista/index.php/RB GA/article/view/1772>. Acessado: Agosto de 2019. BARDIN, Laurence. Análise de conteúdo. 4. ed. Lisboa: Edições 70, 2010.

BARNI, P. E.; FEARNSIDE, P. M.; GRAÇA, P. M. L. A. Simulating deforestation and carbon loss in Amazonia impacts in Brazil's Roraima state from reconstructing highway BR-319 (Manaus-Porto Velho). Environmental Management, v. 55, p. 259:278, Feb, 2015. https://doi.org/10.1007/s00267-014-0408-6

BARTHOLO, R.; SANSOLO, D.G.; BURSZTYN, I. Turismo de base comunitária diversidade de olhares e experiências brasileiras. Rio de Janeiro: Editora Letra e Imagem, 2009.

BEGROW, A. Uma proposta de manejo para a pesca esportiva no médio rio Uatumã Estado do Amazonas, Brasil. 2002. Dissertação (Mestrado em Ciências Ambientais). Manaus, UFAM, CCA, Pós-Grad. em Ciências Ambientais e Sustentabilidade na Amazônia, 2002.

BECKER, B. K. Revisão das políticas de ocupação da Amazônia: é possível identificar modelos para projetar cenários? Parcerias Estratégicas, n. 12, pp. 135-159, setembro 2001. Disponível

em:

$<$ http://seer.cgee.org.br/index.php/parcerias_estr ategicas/article/view/178/172> Acessado: Abril de 2018.

BRASIL. Lei n. 9.985, que regulamenta o art. 225, §12, incisos I, II, III e VII da Constituição Federal, institui o Sistema Nacional de Unidades de Conservação da Natureza e dá outras providências. Brasília, 2000.

BRASIL. Lei $\mathrm{N}^{\circ}$ 6.938, de 31 de agosto de 1981, que Dispõe sobre a Política Nacional do Meio Ambiente, seus fins e mecanismos de formulação e aplicação, e dá outras providências. Brasília, 1981.

BRASIL. Ministério do Meio Ambiente. Disponível em: http://mapas.mma.gov.br/i3geo/datadownload.ht m. Acessado: Novembro de 2018.

DNIT: $\quad$ http://www.dnit.gov.br/mapasmultimodais/shapefiles.Acessado: Novembro de 2018.

ESCADA, M. I. S.; ALVES, D. A. Mudanças de uso e cobertura do solo na Amazônia: impactos socioambientais na ocupação de regiões de fronteira agrícola. Relatório Técnico. São José dos Campos, INPE, 2001.

FEARNSIDE, P. M. Biodiversity as an environmental service in Brazil's Amazonian forests: risks, value and conservation. Environmental Conservation, Volume 26, Issue 4, pp. 305-321, December 1999. https://doi.org/10.1017/S0376892999000429

Deforestation in Brazilian

Amazonia: History, Rates, and Consequences. Conservation Biology, Volume19, Issue 3, Pages 680-688, June 2005. https://doi.org/10.1111/j.1523-1739.2005.00697.x FEARNSIDE， P. M.; LAURANCE，W， F. O futuro da Amazônia: os impactos do Programa Avança Brasil. CIÊNCIA HOJE vol. 31 n $^{\circ} 182$, 2002. Disponível em: <http://philip.inpa.gov.br/publ_livres/2002/Ofutu ro\%20da\%20amazonia.pdf>. Acessado: Janeiro de 2018.

FEARNSIDE, P.M.; GRAÇA, P. M. L. A (a). O EIA-RIMA da rodovia BR-319: decisão crítica sobre a abertura do coração da Amazônia ao desmatamento. Rio de Janeiro: Globo, 2009a (Avulsa). Disponível em: $<$ http://philip.inpa.gov.br/publ_livres/2009/Come ntario-BR319_4.pdf>. Acessado: Janeiro de 2018. FEARNSIDE, P. M.; GRAÇA, P. M. L. A (b). BR319: a rodovia Manaus-Porto Velho e o impacto potencial de conectar o arco de desmatamento à Amazônia central. Novos Cadernos NAEA, v. 12 , no. 1, p. 19-50, junho. 2009b. http://dx.doi.org/10.5801/ncn.v12i1.241

FURTADO, C. S.; MONTEIRO, E. F. A importância do atual sistema de unidades de conservação e terras indígenas na conservação da biodiversidade e contenção do desmatamento na região da $\mathrm{Br}-163$ no Estado do Pará. Florianópolis, Anais da $58^{a}$ Reunião Anual da SBPC, 2006.

HAESBAERT, R. O Mito da Desterritorialização: do "fim dos territórios" à multiterritorialidade. Rio de Janeiro: Bertrand Brasil, 2004.

HUERTAS, C. Entrevista com Carlos Matus. O método PES. São Paulo: Edições Fundap, 1995.

INPA. Instituto Nacional de Pesquisa sobre Amazônia. Disponível em: https://ppbio.inpa.gov.br/mapas. Acessado: Agosto de 2014.

ISA_ Instituto Socio Ambiental. Unidades de Conservação no Brasil. Disponível em: $<$ https://uc.socioambiental.org/pt-br/arp/4859>. Acessado: Abril de 2018.

LIMA, G. $\mathrm{S}$ de. As perspectivas de 
incremento para o turismo no Estado do Amazonas a partir da Recuperação da BR 319. Trabalho de Conclusão de Curso (Graduação em Turismo). Manaus, UEA, ESAT, Curso de Turismo, 2007.

MAGALHÃES, H., BONONI, V.L.R., MERCANTE, M.A. Participação da sociedade civil na gestão de unidades de conservação e seus efeitos na melhoria da qualidade ambiental da região Sudeste do Estado do Mato Grosso do Sul. Acta Scientiarum. Human and Social Sciences. Maringá, v. 32, n. 2, p. 183-192, 2010. https://doi.org/10.4025/actascihumansoc.v32i2.67 61

MORAES, A. C. R. de. Ordenamento territorial: uma conceituação para o planejamento estratégico, In: BRASIL (Min. da Integração Nacional). Brasília, MIN. Para pensar uma política nacional de ordenamento territorial. (anais) Oficina sobre a Política Nacional de Ordenamento Territorial, Brasília, Min. da Integração Nacional p. 43-48, 2005. Disponível

em:

<http://www.mi.gov.br/c/document_library/get_fil e?uuid=3fc31d16-e5f7-46fb-b8cc-

0fb2ae176171\&groupId=24915>. Acessado: Julho de 2015.

MOURA, A. C. M.; MAGALHÃES, D. M. Geoprocessamento no apoio ao plano diretor de desenvolvimento integrado da região metropolitana de Belo Horizonte: acessibilidades, impedâncias e potencialidades territoriais. Rio de Janeiro, Anais do XIV ENCONTRO NACIONAL DA ANPUR. 2011.

G1. Pesca esportiva atrai mais de 10 mil turistas por ano ao Amazonas, diz governo. Portal G1, Disponível em:

<https://g1.globo.com/am/amazonas/noticia/pesca -esportiva-atrai-mais-de-10-mil-turistas-por-anoao-amazonas-diz-governo.ghtml> Acessado: Abril, 2018.

PROENÇA, A. R. G. B. P.; OLIVEIRA, A. P. P. de; JESUS, E. L. de. Turismo de base comunitária no Amazonas: aspectos socioculturais. Curitiba, Caderno de Estudos e Pesquisas do Turismo, v. 5, no.7, p. 19-33, $2016 . \quad$ Disponível em: <http://www2.pucpr.br/reol/pb/index.php/turismo ?dd1=16169\&dd99=view\&dd98=pb>. Acessado: Janeiro de 2018.

RAFESTIN, C. Por uma geografia do poder. São Paulo: Ática, 1993.

REIHANIANA, A. N., MAHMOODA, Z. B., KAHROMB, E., HINC, T. W. Sustainable tourism development strategy by SWOT analysis: Boujagh National Park, Iran. Tourism Management Perspectives, Volume 4, P.P 223-228, October

2012.

https://doi.org/10.1016/j.tmp.2012.08.005.

REZENDE, M.G.G. Governança ambiental na Reserva de Desenvolvimento Sustentável Igapó Açu, Amazonas, Brasil. Dissertação (Mestrado em Ciências do Ambiente e Sustentabilidade da Amazônia). Manaus, Programa de Pós-Graduação em Ciências do Ambiente e Sustentabilidade na Amazônia, UFAM, 2016.

SAITO, E. A. et al. Efeitos da mudança de escala em padrões de desmatamento na Amazônia. Revista Brasileira de Cartografia, no. 63/03, $2011 . \quad$ Disponível em: $<$ http://www.seer.ufu.br/index.php/revistabrasilei racartografia/article/view/43749> Acessado: Janeiro de 2020.

SANTOS, F.P. Reserva Extrativista e Reserva de Desenvolvimento Sustentável, uma pequenagrande diferença. Revista Geonorte, V.6, N.25, Pp. 43-60, 2015. Disponível em:<http://www.periodicos.ufam.edu.br/revistage onorte/article/view/1021170.2015.6.25.3/2125>.

Acessado: Abril de 2018.

SANTOS, M. Por uma geografia nova: da crítica da geografia a uma geografia crítica. $3^{\text {a }}$ edição. São Paulo: HUCITEC, 1986. ISBN 85314-0715-X 1

A natureza do espaço. 2. edição. São Paulo: Editora Hucitec, 1996. ISBN 85-3140713-3

SAQUET, M. A. Reterritorialização e Identidade. In.: MEDEIROS, R. M. V; FALCADE, I. (Orgs). Tradição versus tecnologia: as novas territorialidades do espaço agrário brasileiro. Porto alegre: Ed. da UFRGS, 2009.

SAQUET. M.A. Abordagens e concepções de território. $3^{\text {a }}$. Ed. São Paulo: Outras Expressões, 2013.

SCOLOZZIA, R.; SCHIRPKEB, U.; MORRID, E.; D'AMATOE, D.; SANTOLINI, R. Ecosystem services-based SWOT analysis of protected areas for conservation strategies. Journal of Environmental Management. Volume 146, 15, P.P 543-551 December 2014. https://doi.org/10.1016/j.jenvman.2014.05.040.

SOUZA, A. Americanos são 95\% dos turistas de pesca no Amazonas. PANROTAS, 2014. Disponível em: $<$ https://www.panrotas.com.br/noticia-

turismo/mercado/americanos-sao-95-dos-turistasde-pesca-no-amazonas_106142.html>. Acessado: Abril de 2018. 